\title{
Everyday Magic: Some Mysteries of the Mantlepiece
}

\author{
RALPH MILLS
}

I recently moved into an Edwardian terraced house in a suburb of Leeds, West Yorkshire, England. As a lifelong archaeologist, I

immediately began to investigate my new 110 -year-old home. In a difficult to reach, hidden space beneath the stairs I discovered two longlost, dusty, dented but otherwise undamaged 1920s cloche hats and an ancient Christmas wreath made from dyed feathers and wire. As I dug my backyard archaeological site in order to plant vegetables I found sherds of blue-and-white pottery, fragments of clay pipe stems and a bisque doll's arm. And excitingly I experienced the overwhelming thrill of possessing no fewer than five mantelpieces, slate and iron relics of the days of coal-fired heating.

A contemplation of mantelpieces, their archaeological importance and their associated material culture forms the core of this article. A

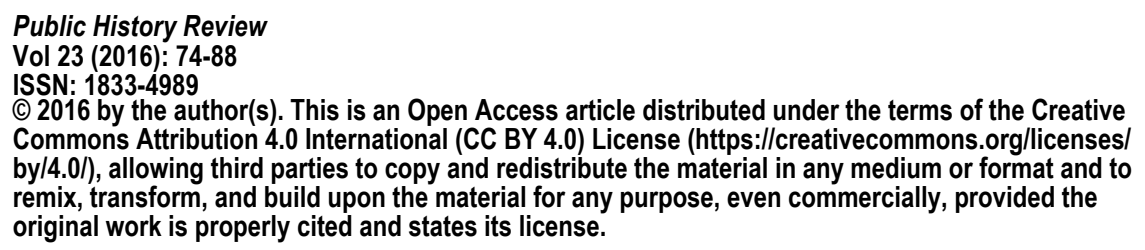


mantelpiece, a surface above a hearth or fireplace, where objects are positioned in close, meaning-rich relationships with each other, can be regarded as an archaeological context, and the objects displayed on it as an archaeological assemblage. The mantelpiece played an important part in the lives of 'ordinary' people in the nineteenth century, and as a historical archaeologist, I concur with Norman Yoffee and Severin Fowles' claim that my chosen field, in analysing physical remains and not privileging elites, 'provides important opportunities for the writing of counternarratives'.' Although mantelpieces rarely survive to feature on archaeological sites, hearths and fireplaces certainly do, as do the objects that may have stood on them. It is the narratives provided by those objects, especially the mass-produced miniatures that are the subject of my ongoing research, that I am attempting to access.

\section{THE ARCHAEOLOGY OF MANTELPIECES}

One day, as she went about her routine do-gooding amongst the mid nineteenth-century poor, Octavia Hill was surprised to be rebuffed by a woman she had encountered in a 'miserable underground kitchen', and to whom she had offered more salubrious accommodation. The lady was reluctant to move because she felt that her 'bits of things' wouldn't look as good in better light. ${ }^{2}$ So important to her were her 'things' and how they were perceived by others that she was willing to turn down the chance of somewhere better to live in order to avoid them being seen as less than special.

Yet her gloomy, subterranean display would probably have earned the scorn of many contemporary commentators. Summing up the nineteenth and early twentieth-century attitudes of many to the possessions of the 'working man', Simon Patten snorted that their homes were 'crowded with tawdry, unmeaning and useless objects; each pointless object is loved, however, as the mark of superiority and success, and its enjoyment energizes the possessor' ${ }^{3}{ }^{3}$

Hill's lady probably lived somewhere like Figures 1 and 2, two recently-excavated examples of basement dwellings from Chorlton-onMedlock, Manchester, England. Figure 1 is part of early nineteenthcentury Ebenezer Plat Terrace, a stamping ground of Friedrich Engels that was demolished in the 1940s and was until recently a car park, and which featured several basement dwellings, complete with slate fireplaces. It is now the site of Manchester University's Graphene Institute, where research is carried out into the properties of one-atomthick layers of graphite. A second example, again discovered beneath a car park, and conveniently next door to my local pub, The Salutation Inn, 


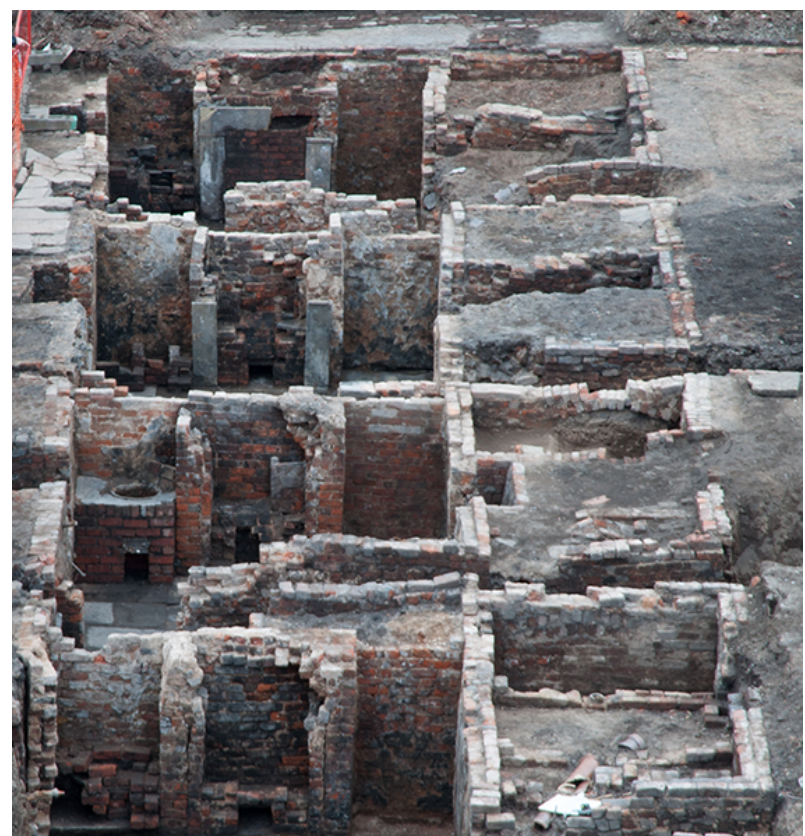

Above: Fig 1 19 $9^{\text {th }}$ century basement dwellings in Ebenezer Plat Terrace, Manchester, showing slate fireplaces, excavated 2013. Below: Fig 2 Remains of nineteenth-century cellar on the site of Cowgill Street, Manchester, with fireplace, sink and water heater, excavated 2014 (photographs, the author)

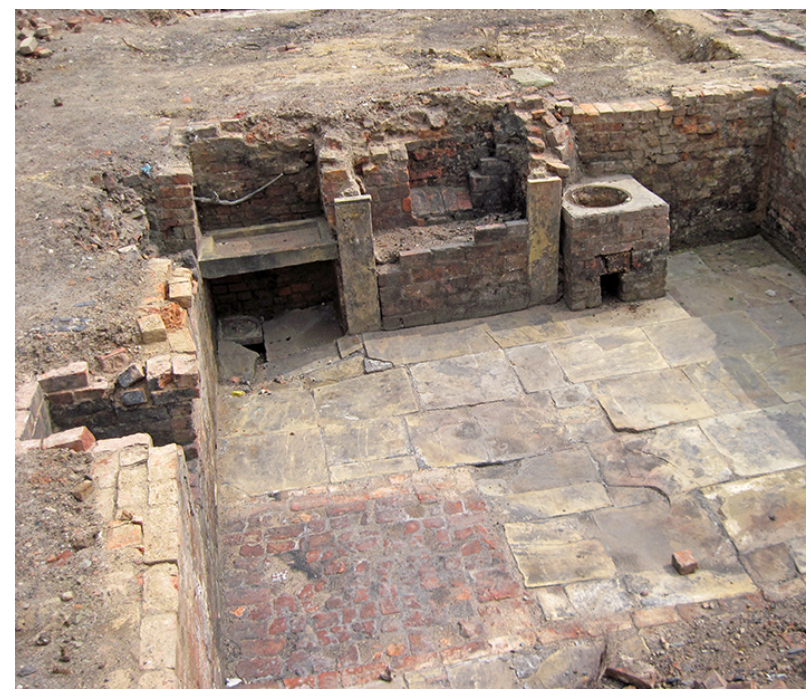

and the site of Manchester Metropolitan University's new Student Union, uncovered more nineteenth century cellars with fireplaces, one complete with water heater and sink (Figure 2).

These sites are significant because they demonstrate that urban archaeology is usually, at least in part, the archaeology of working-class 
contexts, as it delves through demolition debris immediately beneath the surface. Bricketage, foundations, pits and privies destroyed and sealed by nineteenth and twentieth century developments, the residue of slum clearance and hastily-levelled World War Two bomb damage.

Those 'bits of things' were probably proudly displayed on her kitchen's mantelpiece, perhaps made of slate like those discovered in the Manchester basements. A significant example of a nineteenth-century, working-class mantelpiece, an 1850 painting by John Collinson entitled Answering the Emigrant's Letter, hangs in Manchester Art Gallery and shows, above the hearth of a humble cottage, a couple of Staffordshire figurines and, importantly for my research, something that many of us would call a 'toy', a small wooden horse on wheels (Figure 3).

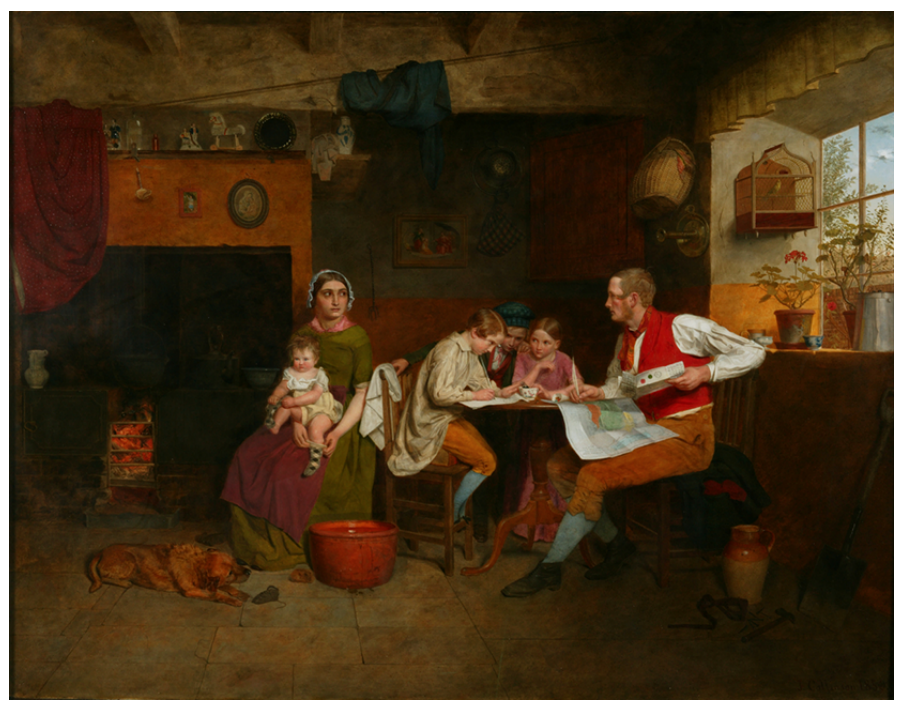

Fig 3 Answering the Emigrant's Letter, John Collinson, 1850 (Image courtesy of Manchester Art Gallery)

\section{The Material CUlture of the MANTElPIECE}

The study of seemingly prosaic objects that were nevertheless regarded as important enough to be displayed at the heart of the home is to research a valuable element of the material culture of the people who originally owned them:

the study of material culture is the study of material to understand culture, to discover the beliefs - the values, ideas, attitudes, and assumptions - of a particular community or society at a given time. 
Material culture provides a way of understanding the social world because of the ways we appropriate it, through living with objects in our everyday lives; interacting with them, using them, allowing them to mediate between us and having quasi-social relationships with them. ${ }^{5}$

'the material culture of everyday life', acknowledges the physical object in all its materiality and encompasses the work of design, making, distributing, consuming, using, discarding, recycling and so on.

As an archaeologist, someone who, to paraphrase Dant, lives with objects, I find that I am fine-tuned to their resonances, recognizing and valuing their ability to communicate the nuances of the existences of those who lived with them in the past.

\section{The MANTElPIECE PROJeCt}

In order to explore what mantelpieces mean to people, and how they might use this space to express themselves, I created an installation Mills' Mobile Mantelpiece, or MMM for short (Figure 4). I provided my made-up mantelpiece with a random selection of charity shop miniatures and asked visitors to the gallery to arrange these objects on the mantelpiece however they wished. I exhibited my mantelpiece in a Manchester art gallery in October and November 2013 as a pilot for a more rigorous public engagement.

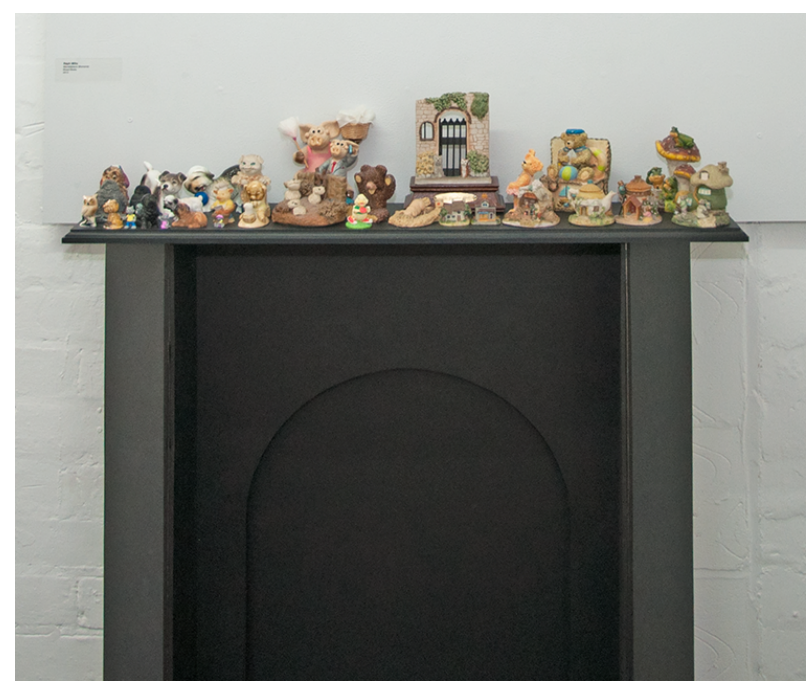

Fig 4 Mills' Mobile Mantelpiece, bearing an array of charity-shop miniature objects, Paper Gallery, Manchester, 2012 (Photograph, the author) 
My experimental work on the mantelpiece follows roughly the approach described by Laurie Wilkie and Kevin Bartoy, which I interpret as proposing that we can learn much by looking at the descendants of those who lived in the past.? In my project I am looking at the descendants of those who lived in the nineteenth century - us - in order to attempt to demonstrate their lived experience. It is those descendants who frequent charity shops and bric-a-brac stalls, and who desire and acquire the miniatures displayed on mantelpieces.

Early results were fascinating. They include one visitor who turned several objects to face the wall, a lady who carefully created a perfectly symmetrical arrangement, a group of young people who had tongue-incheek fun in arranging figurines in compromising positions, and an elderly, wheelchair-bound lady who not only created what she called a 'little village', but also invented an instant narrative in which she strolled down the miniature street and was barked at by a tiny dog.

It seems that the mantelpiece, a simple matt black horizontal surface above a hearth, invited, encouraged and facilitated the action of populating it with objects that would express and communicate something intensely personal, creating three-dimensional narratives that fulfilled something in each individual participant or group.

\section{MEMORIES AT THE HEART OF THE HOME}

The hearth is traditionally regarded as the heart of the home, ostensibly the most important place in the house or the room. It is not surprising that the Latin word for hearth - focus - was adopted by sixteenth-century scientists to describe the meeting point of rays of light or geometric lines. In my English youth, before central heating, the living room was certainly the warmest place in our house, and was where my family spent most time in the winter. So it follows that objects associated with the hearth were and are regarded as part of that centrality, and were often equally consciously placed on the mantelpiece because they possessed particular importance.

The importance of the hearth might be underlined by the resistance of the fireplace and mantelpiece to disappear in the twenty first century, given the ubiquity of central heating and consequent lack of chimneys on modern houses. People will often create a fireplace around an electric or gas heater even if one is not required. And the most dramatic contemporary living room designs often include not only a real or illusory hearth, but also some sort of nearby surface on which to place things. The television, which in the latter half of the twentieth century became the fireplace's main rival as the focus of the living room, in the 
heyday of the bulky cathode ray tube often had a horizontal upper surface that was not only often graced with a lace doily, but was also utilised for displaying the sort of bric-à-brac that would have previously been arranged on the mantelpiece. And now a flat-screen television is more often than not hung above the hearth, sharing focus with the fireplace. In a sense, it is either itself acting as a mantelpiece object, or is replacing the mantelpiece, with what it displays on its flat screen presumably being regarded as central to life in the home.

One of the most frequent features of the nineteenth century chimney breast is a large mirror. What this does is reflect the room and its occupants back at them. It could be therefore said to be mirroring and reinforcing the identity of both room and occupants. So the present-day replacement of the mirror, a reflection of us and our reality, by the flatscreen TV may reflect a sense of identity influenced by what appears on the (big) small screen. I experience discomfort when I encounter a mantelpiece-free fireplace above which hangs an ominous blank black panel. Maybe the empty screen and lack of displayed objects convey nothing about where I am and who I am with?

If a mirror reflects presence and identity, perhaps the objects arranged on the mantelpiece can act in the same way, reflecting meaning back to the occupants of the home. This display might also include visitors, though there are suggestions that outsiders rarely saw the interior of working-class houses. ${ }^{s}$ Alison Clarke quotes Jules Lubbock who asserts that the home was a place of refuge from 'State, government and social reformers', a quiet resistance that might be communicated by some of the miniatures that were placed on the mantelpiece, such as Napoleon and various highwaymen. In the face of criticism of lack of taste, of clutter and tawdry bric-à-brac, perhaps people's stubborn refusal to stop accumulating these ornaments was also a gentle means of resistance.

Another significant aspect of mantelpiece assemblages is their permanence. We are, we are repeatedly told, addicted to novelty, yet seem to be quite happy to look at the same small objects in the same positions on a shelf day after day. Do we need this stability at the heart of the home to mark and strengthen our ownership of this space, and was this true of nineteenth-century families who often repeatedly moved from home to home, taking their mass-produced miniatures with them? People with little disposable income may have used miniatures to create a pocket of material culture over which they could exercise control, both by relative size but also in having the freedom to arrange and manipulate the objects as they willed. At a time when there was little 
security, they could also move this assemblage from place to place and hearth to hearth, re-creating their personal space in each new dwelling.

\section{MEMORIES IN BOXES}

In the nineteenth century the word 'memories' was used to describe damage to objects people brought to pawn shops, imperfections that reduced their value. ${ }^{10}$ Those wrinkles, scuffs, scratches, tears, cracks and chips were memories of past events in the social lives of those objects.

Many of us, myself included, have at home a drawer containing several generations of defunct mobile phones, objects that will no doubt eventually become future archaeological finds. I think our reluctance to recycle these objects, now mere non-functioning chunks of plastic and metal, is because they became infused with memories. We carried them close to our bodies, intimately close, often near enough to absorb some of our warmth. Through them we communicated with loved ones, made dates, broke up relationships, heard good or bad news, shared adventures, worked and played, dealt with life's emergencies and dramas? If we discarded them we perhaps feel that we risk devaluing or losing touch with those activities, even though we often no longer recollect many of them. The object could be described as absorbing and retaining the memories. 'We are particularly well-suited to the act of suffusing an object with emotional value', writes Annalee Newitz ."

Jane Bennett has proposed that things have vibrant 'thing-power', and I'm exploring her ideas as a possible explanation of the influence of the miniatures I study. ${ }^{12}$ If every thing possesses 'power' as defined by Bennett - culminating, she suggests, in their creating the urge in us to collect and hoard them - then miniature objects, in which meaning is concentrated, might logically possess even stronger power to attract our interest, create desire and the wish to have and display them. And it seems that things are indeed powerful, so powerful that we are frequently encouraged to avoid or divest ourselves of them, hence the current popularity of 'de-cluttering'. An article in the January 2014 issue of Psychologies magazine, '100 Moments in Time', exhorted me to 'put clutter in boxes, marked only with the date they were sealed. A year after the date, if you haven't opened it, throw it away, unopened. If you can't remember what was in it, you won't miss it'.

Yet perhaps we need that clutter of things in order to remember, for memories to be stimulated or even for the objects to act as memories? According to Nicolette Mackovicky, Walter Benjamin 'regarded not only memory, but also history, as materialized in objects'. ${ }^{13}$ Perhaps those hidden boxes of clutter are related to Benjamin's 'chaos of memories', ${ }^{14}$ 
that he experienced when unpacking his library? By throwing them away, are we committing an act of deliberate amnesia? This is paradoxical at a time when memory is under attack from the sound-bite, the short-attention span, Alzheimer's disease and a disdain for the disease/pleasure of 'nostalgia'.15 The same observation could have been made during the nineteenth century, when according to Jean-Louis Comolli, people experienced 'a frenzy of the visible' and homes of all classes began to accumulate and display more and more of that muchdisdained 'clutter'."

Ironically, that boxing up and discarding of objects contrasts with the current interest in creating 'memory boxes', which can not only contain and preserve objects that memorialise loved ones or significant events, but even more significantly can replace or restore, even if only temporarily, memories for people who are suffering from dementia. ${ }^{\prime \prime}$ Things become material memories.

I suggest that mass-produced miniatures, on the mantelpiece or elsewhere, play several memory-associated roles. They act as mementos. We acquire them as souvenirs. They act as surrogate humans, adding memories, company and comfort to empty rooms. They may replace memories of an unsatisfactory or non-existent childhood. We use them, and perhaps they use us, as nuclei around which to construct memories and narratives, real or imaginary. Susan Stewart writes that 'the miniature, linked to nostalgic versions of childhood and history, presents a diminutive, and thereby manipulatable, version of experience', and so becomes what Sally Crawford calls a 'curated object of memory'. ${ }^{18}$ Stewart also quotes Bergson, who wrote: 'there is no perception which is not full of memories. With the immediate and present data of our senses, we mingle a thousand details out of our past experience..$^{19}$ In western traditions, objects serve memory in three main ways' writes Marius Kwint. 'Firstly they furnish recollection... Secondly, objects stimulate remembering... Thirdly, objects form records'.$^{20}$

For the lonely, the elderly - those with many memories, and memories that are fading - for the oppressed, for the unfortunate, for the impoverished, an assemblage of small things on the mantelpiece, small objects filled with concentrated 'thing power' can provide security, comfort and company. These aren't recently-invented needs. They would have existed in the nineteenth century when working class people often led lives that left few opportunities for dwelling on the past. So as Kwint writes: 'the relationship of objects with memory has always been meaningful to those with little time to reflect on it'. ${ }^{21}$ Rather than people indulging in passive introspection, it was their homes and the objects displayed in them that became what Anat Hecht described as 'a private 
museum of memory, identity and creative appropriation'. ${ }^{22}$ While Osi Audu speaks of a shrine to the 'inner head' as part of remembering. ${ }^{.2}$ The mantelpiece perhaps acts as a particularly important shrine, one of many in homes - teenage bedroom shrines, shrines to lost childhood, shrines to nostalgia, shrines to annual events, shrines to memory? Indeed presentday so-called 'white witches or wiccans often use the mantelpiece as the location of various types of occult shrines. ${ }^{24}$

These thoughts are important to historical archaeology. For example, miniatures found in a bordello, in a pioneer settlement, in a lumber or gold mining camp, or in a barracks may perhaps indicate the existence of a sort of shrine, to a lost life, to nostalgia, to the occult or a collection of memories.

I used the word 'significantly' when I mentioned, above, the wooden horse on the mantelpiece in Figure 4. What is it doing up high on the mantelpiece, well out of reach of the children who play on the floor? Perhaps it was put up there so that no-one would trip over it. However, I suggest that instead it was placed here, at the heart of the home, because it was special. It was one of those objects that we archaeologists tend to assume belonged to children but may instead have played some other role, perhaps that of the adult toy.

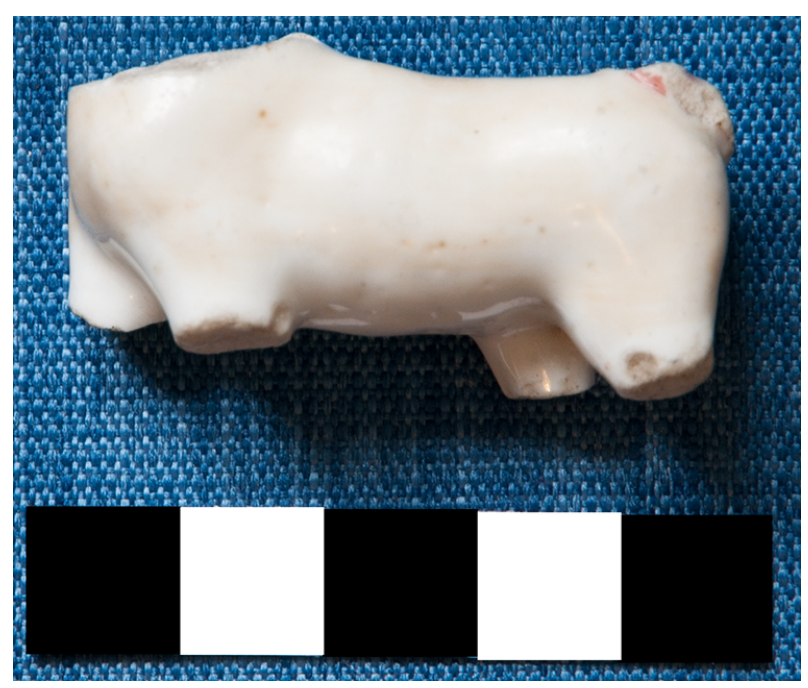

Fig 5 Ceramic miniature animal torso, perhaps of lion (Photograph, the author)

Figure 5 shows an object found in topsoil enriched with night soil from a nearby community that during the nineteenth century was a working class industrial suburb of Nottingham. The artefact is, I suggest, the torso of a miniature lion. It is of course nothing like a real lion. For 
one thing it is tiny, for another it is made from glazed ceramic. Even before it was broken - and thus acquired some additional memories - it wouldn't have been a very realistic lion. Indeed no-one would have thought it to be a real lion. And yet it nevertheless possessed the power of lion-ness, of lion-ality. It was an idea of a lion, a memory of a lion, perhaps owned by someone who had never seen a live lion. That person not only possessed the miniature, but all the concentrated memories of lion-ness that went with it. On their mantelpiece, did it evoke courage, fierceness, pride, all the qualities of a lion? And so reflect the selfidentity of the owner?

\section{What do MANTELPIECE MiniatURES tell ARChaEOLogists?}

When we find miniature objects in archaeological contexts, it might appear at first glance that they were intended to represent the appearance in miniature of things, individuals or groups of individuals, real or imaginary: that is, they were 'portraits'. I would question this, given the often-low quality of sculpting, the lack of detail (abstraction), the interchangeability of figurine identities - the same mould was often used to represent several very different characters - and the fact that many originals were imaginary.

I suggest that they were intended to represent the 'idea' of an individual or group or building. A figurine of Nelson was therefore not meant to be a portrait, but made the viewer/owner think about Nelson and whatever associations that might inspire - including jingoism, admiration, heroism and patriotism. Miniatures acted as images rather than accurate models, indeed figurines were often called 'images' in the nineteenth century. So the challenge for archaeologists is to decide what ideas these objects represented.

Much more than small decorative knick-knacks, counterintuitively, miniatures were and are assumed to have 'insides', to possess 'life', rather than being merely lumps of clay or metal. That 'life' meant that the small broken thing found in a cesspit may have once communicated identity, or humour, or bawdiness, or religious or political allegiances, or superstition.

\section{MANTELPIECES AND MAGIC}

The chimney, with the fireplace at its base, is an always-open portal to the outside world through which evil spirits and otherworldly and unwelcome entities could gain access to the household. The mantelpiece might therefore be associated, even unconsciously, with the folk memory and superstition that has been associated with the hearth since at least 
medieval times: for example Welsh and Manx fairies were rumoured to take over the fire once the family had gone to bed. ${ }^{25}$ Outside in many a garden stands a vanguard of small figures, gnomes, ready to scare away any malevolent spirits. But should an invader reach the chimney and arrive in the hearth, they then face a posse of dogs, small humans, lions, frogs or whatever, all wide-eyed and alert, guarding the entrance into the vulnerable world of the household.

It is rare that we see a mantelpiece occupant with closed eyes, asleep perhaps, or looking in any direction other than ahead. Indeed, the eyes of, for example, ceramic Staffordshire dogs and plaster of Paris cats are often exaggeratedly large, eerily like the eyes of medieval gargoyles and grotesques as well as the apotropaic eyes painted on the prows of Mediterranean fishing boats. Cats, roosters, dogs and other animals have been reputed by many cultures to ward off evil sprits and deflect the evil eye, and it is logical to replace living animals with a permanent, static representation, often in miniature.

Although not by the nineteenth century overtly magical, miniatures nevertheless appear to possess 'magic' properties, to be associated with superstition, to be carried as charms, to be the basis of small, disparate collections that might be regarded as 'shrines', which might explain their continued popularity in the face of criticism of clutter and bric-à-brac. Mirrors, which, as noted above, acted as a frequent backdrop to the mantelpiece, were also regarded as discouraging to evil spirits. I doubt whether flat screen TVs have the same effect.

Miniature tripod cauldrons present another curious example. Already mostly obsolete in the nineteenth century, when few urban houses had a fireplace big enough to allow the installation of a fire crane, and when many homes possessed small ranges and others engaged in communal cooking, the tripod cauldron, at least as its miniature version, continued to play a seemingly important role. Multiple examples are listed in the English Portable Antiquities Scheme (PAS) database, which is maintained to collect artifact information submitted voluntarily by metal detectorists and other 'treasure hunters'. As finds grubbed up with no regard to stratigraphical relationships, those in the PAS database are dated pretty much by guesswork, but it is significant that they occurred on nineteenth century mantelpieces and are still collected today, at least 200 years after they were last in common use. Are they examples of nostalgia? Or sentimentality? Or could it be an unconscious association with magic and superstition? Neela Banerjee notes that on a wiccan mantelpiece are: 'two candles, a tiny cauldron, four stones to represent the elements of nature and a small amethyst representing her spirit' ${ }^{2}$ 
Not many of us remember cauldrons being used. So these miniature cauldrons might represent fragments of memory originating in the distant past.

I'm not suggesting that people - other than wiccans perhaps consciously create these collections of objects as shrines, just as I don't think that garden gnomes are bought deliberately to repel evil spirits. But perhaps there is a sort of material folk memory present in these objects. For example, the writer of a blog titled 'Copper and Wood' acquired a Staffordshire dog figurine, which she placed on her hearth along with a plastic miniature dinosaur: 'No-one will steal my fire now!', she blogged on 31 March 2013, sharing a sentiment that would be understood by someone from the Neolithic.

\section{CONCLUSION}

Figurines and other miniatures are complex objects that were created in order to represent thought and behaviour rather than simply mirror solid reality. I've introduced a group of miniature objects that are often associated with the mantelpiece, that all-important focus of so many homes and so many rooms, both now and in the recent past. These objects seem to have power, a power that their small size appears to concentrate, so they are alluring, thought-provoking performers on the stage of the mantelpiece that offer us comfort and pleasure and keep us company, as well as communicating back to us our sense of self. They not only trigger memories but may also sometimes encapsulate them, absorbing them perhaps by osmosis or coming with a ready-installed set, and thus have the power, or agency, to be memories.

These everyday mass-produced miniature objects, which on most urban archaeological sites occur in working-class contexts, are worthy of detailed study and thought, rather than being merely 'evocative' knickknacks. They are artefacts that can communicate 'soft' data about those in the recent past who desired and acquired them, as well as those who created and manufactured them.

These objects can influence the thoughts and behaviours of those who encounter them. Thus, unlike more utilitarian archaeological finds, mantelpiece miniatures, as expressions of taste, of delight, of aspiration, of humour, of imagination and other intangibles, may provide valuable insights into the everyday thinking of 'ordinary' people.

Elizabeth Scott uses the phrase 'those of little note' to call for more attention to be given to individuals 'considered of little importance, not worthy of "notice," by the dominant social, political, and economic group in a past society... those considered not worth noting or writing 
about... who therefore are not as visible to us in the written records... those written about less frequently, or little noted, by historical archaeologists' ${ }^{\prime 2}$ The everyday decorative objects discovered on archaeological sites, and often regarded as mere curiosities, may instead provide resources to enable us to learn more about 'those of little note'.

Some mantelpiece objects may even possess a sort of magic memory, or memory of magic. But on that subject I should share some appropriate words from a Terry Pratchett children's novel: 'Magic is just a way of saying "I don't know"'.28

\section{ENDNOTES}

' Norman Yoffee and Severin Fowles, 'Archaeology in the Humanities', Diogenes 229230, 2011, pp51-77.

Octavia Hill, Homes of the London Poor, 1875, p86.

Bill Brown, A Sense of Things: The Object Matter of American Literature, University of Chicago Press, Chicago, 2003, p33.

‘ Jules David Prown, 'The Truth of Material Culture: History or Fiction?', in Jules David Prown and Kenneth Haltman (eds), American Artifacts: Essays in Material Culture, Michigan University Press, East Lansing, 2000, pp11-27.

${ }_{5}^{5}$ Tim Dant, Material Culture in the Social World, Open University Press, Buckingham, 1999, p201.

'Judy Attfield, Wild Things: The Material Culture of Everyday Life, Berg, Oxford, 2000, p3.

'Laurie Wilkie and Ken Bartoy, 'A critical archaeology revisited', in Current Anthropology, vol 41, 2000, p756.

'Alison J Clarke, 'The Aesthetics of Social Aspiration', in Daniel Miller (ed), Home Possessions: Material Culture behind Closed Doors, Berg, Oxford, 2001, p30.

ibid, p24.

${ }^{10}$ Attfield, op cit, p125.

"Annalee Newitz, 'My Laptop', in Sherry Turkle (ed), Evocative Objects: things we think with, MIT Press, Cambridge MA, 2007, pp88-9.

${ }_{12}$ Jane Bennet, Vibrant Matter: a political ecology of things, Duke University Press, Durham NC, 2010.

${ }^{13}$ Nicolette Makovicky, 'Closet and Cabinet: Clutter as Cosmology', in Home Cultures, vol 4, issue 3, 2007, pp287-310.

"Walter Benjamin, Illuminations, (edited by Hannah Arendt) Schoken Books, New York, 1969, p60.

${ }^{15}$ Linda Marilyn Austin, Nostalgia in Transition, 1780-1917, University of Virgina Press, Charlotteville, 2007, p3.

${ }^{16}$ Jean-Louis Comolli, 'Machines of the Visible', in Teresa de Laurentis and Stephen Heath (eds), The Cinematic Apparatus, MacMillan, Basingstoke, 1980, pp121-141.

"See for example Help for Alzheimer's Families website available at: http:/ / www.helpforalzheimersfamilies.com/alzheimers-dementiadealing/capturing-memories/memory-box/ (accessed 24 December 2015).

${ }^{18}$ Susan Stewart, On Longing: Narratives of the Miniature, the Gigantic, the Souvenir, the Collection, Duke University Press, Durham, NC, 1983, p69 and Sally Crawford, 'The Archaeology of Play Things: Theorising a Toy Stage in the 'Biography' of Objects', Childhood in the Past: An International Journal, vol 2, issue 1, 2009, pp55-70.

19 Susan Stewart, 'Prologue: From the Museum of Touch', in Marius Kwint, Christopher Breward, and Jeremy Aynsley (eds), Material Memories: Design and Evocation, Berg, Oxford 1999, pp18-36. 
${ }^{20}$ Marius Kwint, 'Introduction: The Physical Past', in Marius Kwint, Christopher Breward, and Jeremy Aynsley (eds), Material Memories: Design and Evocation, Berg, Oxford, 1999, pp1-16.

${ }^{21}$ ibid, p5.

"Anat Hecht, 'Home Sweet Home: Tangible Memories of an Uprooted Childhood', in Daniel Miller (ed), Home Possessions: Material Culture behind Closed Doors, Berg, Oxford, pp123-145.

${ }^{23}$ John Mack, The Museum of the Mind, The British Museum Press, London, 2003, p25.

${ }^{4}$ See, for example, Neela Banerjee, 'Wiccans Keep the Faith With a Religion Under Wraps', New York Times 16 May 2007. Available at:

http: / / www.nytimes.com/2007/05/16/us/16wiccan.html?_r=0

${ }_{25}$ John Rhys, Manx Folklore and Superstitions, Chiollagh Books, Önchan, 1994, p2.

${ }^{26}$ Banerjee, op cit.

${ }^{27}$ Elizabeth M Scott (ed), Those of little note: gender, race, and class in historical archaeology, University of Arizona Press, Tucson, 1994, p3.

${ }_{28}$ Terry Pratchett, Nation, Random House, London, 2008, p175. 